\title{
Self-Medication among Rural Population: A Present Day Challenge!!!
}

\author{
Kadas Shashanka ", Dr Shruti Kardalkar"*, B.S. Navya ${ }^{* * *}$, Dr Harikrishna B.N ${ }^{* * *}$ \\ ${ }^{*}$ Research Scholar in social work, Osmania University, Hyderabad, Telangana, India. \\ ** MD, Assistant Professor, Department of Community Medicine, ESIC Medical College and Hospital, Hyderabad, Telangana, India. \\ ${ }^{* * * *}$ Student, MBBS., ESIC Medical College and Hospital, Hyderabad, Telangana, India. \\ ***** MD, Assistant Professor, Department of Community Medicine, ESIC Medical College and Hospital, Hyderabad, Telangana, India \\ DOI: 10.29322/IJSRP.12.01.2022.p12104 \\ http://dx.doi.org/10.29322/IJSRP.12.01.2022.p12104
}

\begin{abstract}
Background: Self-medication is a global phenomenon and potential contributor to human pathogen resistance to antibiotics and adding to the woes of public health. The World Health Organization (WHO) Expert Committee on National Drug policies in 1995 stated that Self-medications is widely practiced in both developed and developing countries. This study was undertaken to assess the self-medication practices and to relate factors influencing it.

Methodology: A community based cross sectional study was conducted among rural adult population. A pre-designed and pretested questionnaire was developed, data were collected and distributions of responses were presented as frequencies and percentages. Chi-square was applied.

Results: A total of 187 adults took part in the study, majority of $64.71 \%$ were aged $26-33$ years, $58.28 \%$ were females, $49.73 \%$ literates, $45.45 \%$ lower middle class joint families were predominant and maximum belonged to class $\mathrm{V}$ socioeconomic status as per Modified B G Prasad Classification. The prevalence of self-medication was between $50-70 \%$ for the common problems of joint pains, headache and fever followed by diarrhoea. The significant factors were male gender, younger age group and absence of health facility near to the residence $(\mathrm{p}<0.005)$

Conclusion: Self-medication has become an alarming concept which needs to be addressed through holistic approach of adequate awareness and education and improvising on the authorized dispensing of drugs. There is a necessity for behaviour changes related to self-medication practices and adhere to strict regulatory and managerial strategies to make health care easily accessible and more cost-effective.
\end{abstract}

Index Terms- Adult, Global, Health, Rural, Self-medication.

\section{INTRODUCTION}

$\mathrm{S}$ elf-medication is a global phenomenon and potential contributor to human pathogen resistance to antibiotics and adding to the woes of public health. [1]The World Health Organization (WHO) Expert Committee on National Drug policies in 1995 stated that Self-medications is widely practiced in both developed and developing countries. [2]

The prevalence of irresponsible self-medication is high all over the world, and it is a very common practice in women those who live alone both in the economically deprived communities as much as it is in the economically privileged. [3, 4] Globally, consumers commonly reach for self-care products to help them treat their common health problems which include fever, body pains, indigestion, diarrhoea, vomiting, cough, and upper respiratory tract infections. [5]

Self-medication is very common among individuals in many developing countries, and despite the growing research interest on the topic, not much is known about its major determinants.[6] Evidence indicates that rural residents have a limited access to healthcare, and that rural areas are underserved by primary care physicians.[7].

Inappropriate self-medication is more likely to occur among people in rural areas with poor terrain, limited health facilities, high illiteracy level and poverty, extent of inappropriate as well as appropriate self-medication in a rural community need to be assessed. This study was aimed at assessing self-medication among residents of rural field practice area of a tertiary medical college Hyderabad, Telangana.

\section{OBJECTIVE}

To assess the self-medication practices and relate factors influencing it.

\section{MATERIALS AND METHODS}

\section{Study design \& setting:}

A community based, cross-sectional study was conducted from Aug-Oct 2020 for three months among adults residing in rural area from $1 \mathrm{yr}$, which is the field practice area of Rural Health Training Centre attached to a tertiary care hospital in Hyderabad, Telangana, India.

\section{Inclusion and exclusion criteria:}

Adults residing in the study area for more than one year and gave consent on a voluntary basis to participate in the study were included. People who are on medication for chronic diseases (Hypertension, diabetes, chronic heart dieses etc.) were excluded and also people who could not be contacted after three visits were excluded from taking part in the study

Sampling size: 
Convenient sample size of 200 adults in the age group 18 to 60 years were considered. Out of these participants 13participants couldn't be traced even after three visits to their houses so they were excluded. Final sample size was estimated to be 187 .

\section{Data collection:}

Data were collected by interviewing all 187 study participants by conducting house-to-house survey using a predesigned and pre-tested semi structured proforma, which include part 1 socio-demographic profile like age, gender, occupation, and socioeconomic status, part 2 questions on self-medication was also collected.

The questionnaire used in the study was translated to vernacular language and validated by the investigators. Data was collected after obtaining informed consent on voluntary basis and assuring the confidentiality face to face interview was conducted. Data analysis was done using SPSS software version 22.0. Descriptive statistics and frequencies were calculated. Study was conducted after taking Institutional Ethical Committee approval.

\section{RESUlts:}

A total of 187 Adults population residing in the rural area participated in the study. The socio-demographic characteristics of the study participants are shown in the table .1 , where majority of $64.71 \%$ were in the age group of 26-33years. A maximum of $58.28 \%$ were females, $50.27 \%$ were illiterates and $45.45 \%$ of the participants belong to lower class (class IV) according to BG Prasad's classification.

Table .2 depicts the details of self-medication practices. $64 \%$ of the participants said they practised self-medication because of the location of health care services more than $2 \mathrm{kms}$ from their house, where as $71 \%$ participants said they are practising selfmedication for normal fever, body pains $(66 \%)$, don't want to visit doctor $(61 \%), \quad$ cost effective(68\%), previous prescription(52\%),earlier experience(57\%),very mild illness $(76 \%)$ and non availability of medical $\operatorname{staff}(26 \%)$ respectively. Over all $50-70 \%$ of the participants practise selfmedication and the remaining doesn't have the idea of practising self-medication.

Fig: 1 shows the distribution of study participants based on the type of drugs used in practising self-medication. Highest being the analgesics $55.61 \%$, followed by antipyretics $50.26 \%$, antacids $43.85 \%$, Multivitamins $42.78 \%$ and the lowest being the sleeping pills $12.83 \%$, this is because of asking for the prescription by the local pharmacy.

Table3: showing association between the related factors and practise of self medication. Significant association was found between male genders ( $p$-value 0.001867$)$, age group $\leq 25$ years (p-value 0.00032 ), nearby health facility absent (p-value 0.00088 ) and practising of Self-medication

\section{DISCUSSION:}

Present study shows the distribution of study participants $(64.71 \%)$ are in the age group between 26-33years which is similar to Marak et al 64.8\% [8] and Aqeel et.al [9] higher when compared with the study done by Ayanwale, et al. [10] ( 52.5\%).
Our study found prevalence of practice of self-medication is between 50-70\% among the rural population. High percentage of self-medication among the population might be due to the factors such as difficult road communication in the area, weak public health infrastructure, and peoples' trust in local chemists. Similar community-based, cross-sectional study in rural areas by Ahmed et al. had found that $50 \%$ of respondents practiced self-medication. [11]

While Keshari et al. and Banjara and Bhukya had found very high percentages of (69\% and 80\%, respectively) self-medication practices among the rural population. [12, 13]

In our study, practice of self-medication was found to be more among the females

$58.28 \%$ than the males. Which is higher than the studies done by Ayanwale, et al [10] Marak et al. [8] $48.4 \%$ \& $47.2 \%$ respectively.

Present study shows $71 \%$ participants said they are practising self-medication for normal fever, body pains $(66 \%)$, don't want to visit doctor $(61 \%)$, cost effective(68\%), previous prescription $(52 \%)$, earlier experience $(57 \%)$, very mild illness $(76 \%)$ and non availability of medical staff $(26 \%)$ respectively. Over all $50-70 \%$ of the participants practise self-medication. It is higher than Hong Kong China (32.5\%) [14], while lower than Slovenia (92.3\%) [15] And the remaining doesn't have the idea of practising selfmedication. Marak et al. [8] study shows fever (17.5\%) body pain $(13.7 \%)$, Don't want to see doctor $(27 \%)$, monetary constraints( $5 \%$ ), Previous prescription ( $21.5 \%)$, earlier experience $(15.5 \%)$, mild illness $(30 \%)$ respectively.

Aqeel et.al [9] study shows $41.8 \%$ reported "mild illness" as the most common reason, followed by "economical" $21.2 \%$, "previous experience" $19.6 \%$, "lack of health care facilities" as $12.4 \%$ respectively.

In our study it is observed that $55.61 \%$ used analgesics, followed by antipyretics $50.26 \%$, antacids $43.85 \%$, Multivitamins $42.78 \%$ as practise of self medication, and the lowest being the sleeping pills $12.83 \%$ this is because of asking for the prescription by the local pharmacy.

Aqeel et.al [9] study shows $61.1 \%$ Analgesics were determined as the most likely group of medicines used for selfmedication followed by multivitamins $7.2 \%$, drugs used in GIT disorders $5.2 \%$, and sleeping pills $0.7 \%$ findings are much lower than our study.

\section{CONCLUSION}

There is a necessity for behavior changes related to self-medication practices and adhere to strict regulatory and managerial strategies to make health care easily accessible and more cost-effective.

Frequent awareness programmes and IEC should be done on regular basis in the community about the importance consulting doctor before any drug use. Cost effective health care services should be practised and are made easily available to the community, so that receiving healthcare becomes easily accessible and less time consuming.

\section{Strength and Limitations}

The study being carried out in a rural population as sample might be helpful to bring out the findings although it had certain limitations such as small sample size, consideration of limited

This publication is licensed under Creative Commons Attribution CC BY 
variables, and exclusion of traditional and AYUSH medication practices.

\section{REFERENCES}

[1] 1. Rangari GM, Bhaisare RG, Korukonda V, Chaitanya YL, Hanumanth N. Prevalence of self-medication in rural area of Andhra Pradesh. J Family Med Prim Care 2020;9:2891-8.

[2] 2. Limaye D, Limaye V, Fortwengel G, Krause G. Self-medication practices in urban and rural areas of western India: a cross sectional study. Int J Community Med Public Health 2018;5:2672-85.

[3] 3. FilhoL, Antonio I, Lima-CostaMF, UchoaE.Bambuiproject: A qualitative approach to self medication. Cad Saude Publica 2004; 20:1661-9.

[4] 4. Hughes CM, McElnay JC, Fleming GF. Benefits and risks of selfmedication. Drug Saf 2001;24:1027-37.

[5] 5. Arikpo GE, Eja ME, Enyi-Idoh KH. Self-medication in rural Africa: The Nigerian experience. Internet $\mathbf{J}$ Health 2010;11:1. Available from: http://www.ispub.com/IJH/11/1/5032. [Last accessed on 2021 Dec 2].

[6] 6. Awad A, Eltaved I, Matowe L, Thalib L. Self-medication with antibiotics and antimalarials in the community of Khartoum State, Sudan. J Pharm Sci 2005;8:326-31.

[7] 7. Global Health University. Unite for Sight: Urban Versus Rural Health. Available from: http://www.uniteforsight.org/../urban-rural-health. [Last accessed on 2021 Dec 2].

[8] 8. Marak A, Borah M, Bhattacharyya H, Talukdar K. A cross-sectional study on self-medication practices among the rural population of Meghalaya. Int $\mathbf{J}$ Med Sci Public Health 2016;5:1134-1138.

[9] 9. Aqeel T, Shabbir A, Basharat H, Bukhari M, Mobin S, Shahid H, et al. Prevalence of self-medication among urban and rural population of Islamabad, Pakistan. Trop J Pharm Res 2014;13(4):627-33.

[10] 10. Ayanwale MB, Okafor IP, Odukoya OO. Self-medication among rural residents in Lagos, Nigeria. J Med Trop 2017;19:65-71.

[11] 11. Ahmed A, Patel I, Mohanta GP, Balkrishnan R. Evaluation of self medication practices in rural area of town sahaswan at northern India. Ann Med Health Sci Res 2014;4: S73-8.
[12] 12. Keshari SS, Kesarwani P, Mishra M. Prevalence and pattern of selfmedication practices in rural area of Barabanki. Indian J Clin Pract 2014; 25(7):636-9.

[13] 13. Banjara SK, Bhukya KD. To estimate the prevalence of self medication in rural areas of Medak District of Telangana. Indian J Appl Res 2014; 4(11):412-4.

[14] 14. Lam CL, Catarivas MG, Munro C, Lauder IJ. Selfmedication among Hong Kong Chinese. Soc Sci Med. 1994; 39(12): 1641-1647.

[15] 15. Klemenc-Ketiš Z, Hladnik Ž, Kersni J. A cross sectional study of sex differences in self-medication practices among university students in Slovenia. Coll Antropol. 2011; 35 (2): 329-334.

\section{AUTHORS}

First Author - Kadas Shashanka, Research Scholar in social work, Osmania University, , Telangana, India., Email:

ks9474601@gmail.com

Second Author - Dr Shruti Kardalkar, MD, Assistant Professor, Department of Community Medicine, ESIC Medical College and Hospital, Hyderabad, Telangana, India., Email:

drshru.kardalkar@gmail.com

Third Author - B.S. Navya Student, MBBS. ESIC Medical College and Hospital, Hyderabad, Telangana, India., :

navyasrinivas9642@gmail.com

Fourth Author - Dr Harikrishna B.N, MD, Assistant Professor, Department of Community Medicine, ESIC Medical College and Hospital, Hyderabad, Telangana, India.,Email:

hari.bn@gmail.com

Correspondence Author - Dr Harikrishna B N, Assistant Professor, Department of Community Medicine, ESIC Medical College and Hospital, Hyderabad, Telangana, Ph: +91 8008223332, Email: hari.bn@gmail.com

Table 1: Socio demographic profile of study participants $(n=187)$

\begin{tabular}{|l|l|l|}
\hline Age (years) & Number (n) & Percentage (\%) \\
\hline$\leq 25$ & 38 & 20.73 \\
\hline $26-33$ & 121 & 64.71 \\
\hline$\geq 34$ & 28 & 14.56 \\
\hline Gender & & \\
\hline Males & 78 & 41.72 \\
\hline Females & 109 & 58.28 \\
\hline Education & & \\
\hline Illiterates & 94 & 50.27 \\
\hline Literates & 93 & 49.73 \\
\hline Socioeconomic status (BGprasads classification ) & & \\
\hline
\end{tabular}




\begin{tabular}{|l|l|l|}
\hline Upper class (class I) & 5 & 2.70 \\
\hline Upper middle (class II) & 9 & 4.81 \\
\hline Lower middle (class III) & 36 & 19.25 \\
\hline Upper lower (class IV) & 52 & 27.80 \\
\hline Lower class ( class V) & 85 & 45.45 \\
\hline
\end{tabular}

Table 2: Factors responsible for self-medication practise among study participants (n=187)

\begin{tabular}{|l|l|l|}
\cline { 1 - 2 } Factors & \multirow{2}{*}{ Numbers } & \multirow{2}{*}{ Percentage (\%) } \\
\cline { 1 - 2 } Health care services & & \\
\cline { 1 - 2 } Far ( > 2 kms) & 119 & 64 \\
\hline Near (<2 kms) & 68 & 36 \\
\hline Normal fever & 132 & 71 \\
\hline Body pains & 124 & 66 \\
\hline Don't want to visit doctor & 114 & 61 \\
\hline Cost-effective & 128 & 68 \\
\hline Previous prescription & 98 & 52 \\
\hline Earlier experience & 106 & 57 \\
\hline Non availability of medical staff & 48 & 26 \\
\hline Very mild illness & 142 & 76 \\
\hline
\end{tabular}

Note: Number \& Percentages of self-medication practise only are represented in the table. 


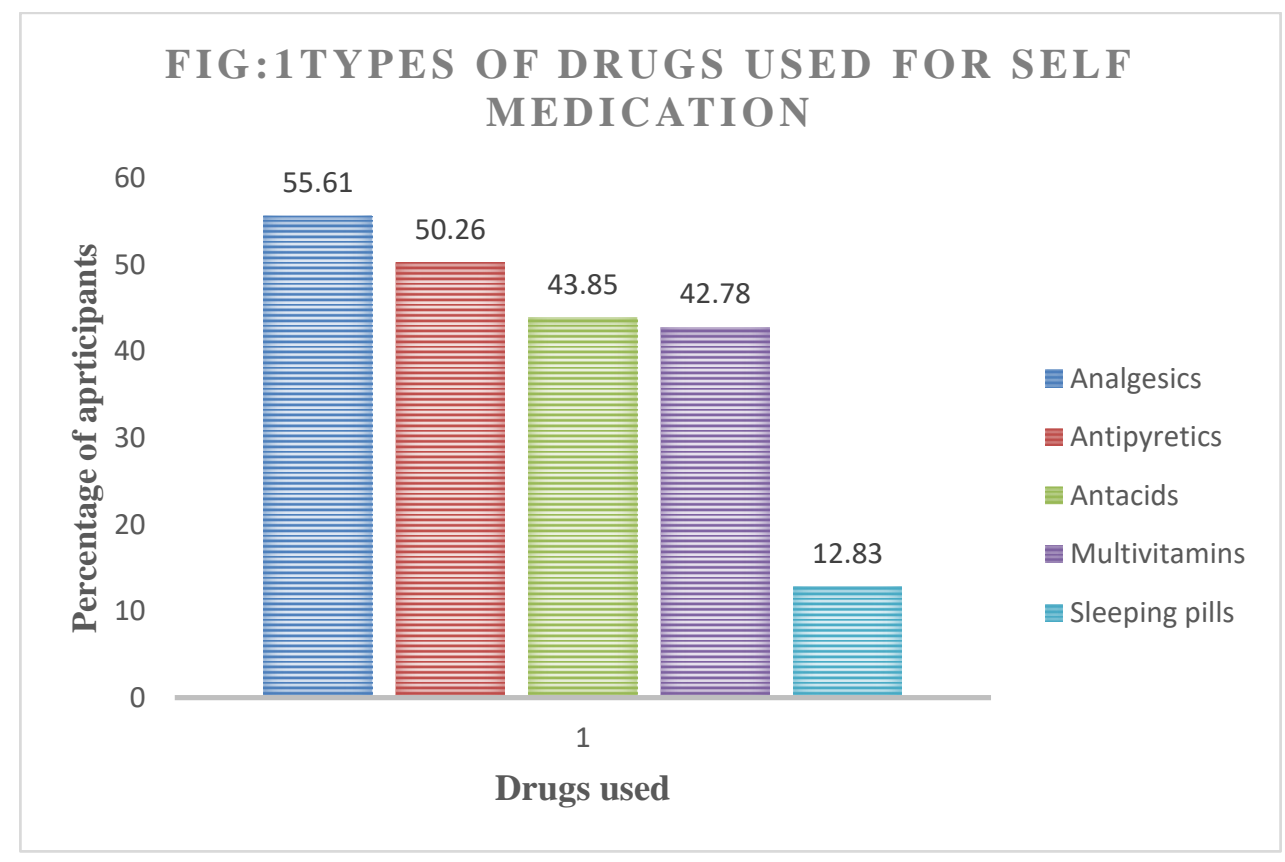

Table3: Association between related factors and self-medication practices.

\begin{tabular}{|l|l|l|l|}
\hline Parameter & $\chi^{\mathbf{2}}$ & df & *p value \\
\hline Male gender & 12.5669 & 1 & 0.001867 \\
\hline Young age $(\leq 25 \mathrm{yr})$ & 21.2238 & 2 & 0.00032 \\
\hline Nearby Health facility Absent & 15.3799 & 1 & 0.00088 \\
\hline
\end{tabular}

